\title{
Climate Changes Consequences from Sun-Earth Connections and Anthropogenic Relationships
}

\author{
Marilia Hagen', Anibal Azevedo \\ ${ }^{1}$ Instituto de Física, Universidade Federal Fluminense, Niterói, Brazil; ${ }^{2}$ Faculdade de Ciências Aplicadas da Unicamp, \\ Limeira, Brazil
}

Correspondence to: Marilia Hagen, mariliadtavares@gmail.com

Keywords: Climate Change, Sun-Earth Connections, Troposphere, Anthropogenic

Received: January 4, 2022 Accepted: February 7, $2022 \quad$ Published: February 10, 2022

Copyright $\odot 2022$ by author(s) and Scientific Research Publishing Inc.

This work is licensed under the Creative Commons Attribution International License (CC BY 4.0).

http://creativecommons.org/licenses/by/4.0/

\section{(c) (i) Open Access}

\section{ABSTRACT}

This paper is a study to understand how climate changed last fifty years. There are two theories: the first one considers the solar variability and the influence of those alterations on climate; the second one blames human activity and the consequences on temperatures and disruption on the environment created by humans. Our conclusions pointed out that dimensions involved between Earth and Sun, and Earth/Atmosphere, the second one can disturb the temperature on Earth's surface and make seasonality variations impossible to be explained only by Sun/Earth connections.

\section{INTRODUCTION}

Initially is necessary to understand that the most critical factors for the climate on Earth are the interaction Sun-Earth and the human interference on the atmosphere and consequent alterations on the environment.

\subsection{Interaction Sun-Earth}

Our preliminary studies of the Sun, Moon, Earth connections [1-3] taught that the phenomena between the three bodies are mechanical or electromagnetic, independent from human interferences.

Our former papers link Solar events related to the Earth's magnetosphere and discuss the possibility of some correlation with earthquakes.

However, the Sun is a powerful energy source in the three-body system (Sun, Moon, Earth), the effects are slower than human interference on the climate.

Solar changes are perceived during a year, like seasons, intense coronal mass ejections, flares. However, in the case of sunspots, the evolution of one cycle takes a decade.

Solar cycles and seasons are cyclical, one has a decade variation, and the other repeats annually.

Scientists have struggled to understand how the solar phenomena observed on the Sun affect the 
Earth and the consequences for the climate.

The solar perturbations have slower effects on Earth, and interference in the phenomena evolution is impossible to change by people. Moreover, other factors can be added to disturbances on the climate to the entire USA, such as disposal of hazardous substances, non-recyclable components, nuclear waste, discarding of plastics.

\subsection{Human Interference}

The wildfires events created by anthropogenic disturbances in the environment are partially related to the other two occurrences, floods and droughts. The wildfires must start with an electrical discharge, floods, and droughts depending on the atmospheric interactions in the troposphere. Wildfires release gases from the burning vegetation to the atmosphere; those take an almost vertical trajectory to the stratosphere. The wildfires analyzed in this study occurred in the conterminous USA (Northern Hemisphere); according to the data, $85 \%$ are due to human activity and arise during most in the Summer or Fall.

The emission of gases and other pollutants is released to the troposphere, a layer reaching ten kilometers from the ground. This region naturally recycles some dangerous discharges created by humans; however, there is a massive emissions enhancement by humans, and the region keeps the gases trapped, unable to recycle all by natural effects, the troposphere working as a semi-adiabatic system. The warmer troposphere holds more moisture causing heavier precipitation, overall collapsing the meteorological conditions on the ground [4-9]. Therefore, the three events analyzed partially intercorrelated, wildfires, flooding, droughts. Humans are responsible for most of the wildfires happening in the conterminous USA. The other two hazards' events, as droughts and floods, have connections with the wildfires, not all of them but some. These are the first pieces of evidence of anthropogenic alteration in the climate. Other human factors contribute daily to the climate as deforestation places devastation of dense vegetation flood easier or become deserts. Human changes happen on the entire planet, most on the continental surface and oceans, three-quarters of Earth.

Let us turn attention to describing solar variability and its effects on the Earth. The main forces among Sun, Moon, Earth are mechanical or electromagnetic. Considering the distances, the power Sun over Moon, Earth is negligible; the active forces are most electromagnetic. On the other hand, the magnetic field created by Sun is $0.5 \mathrm{G}$, the double of the electromagnetic field from Earth affecting both the Moon, Earth. The other important mechanism from Sun/Earth interactions is the seasons determined by the planet's axis position concerning the Earth's rotation around the star.

\subsection{Solar and Human Interactions and Their Impacts on the Environment}

Anthropogenic perturbations are detected in years or decades, while the Solar correlations are perceived much slower. Human modifications can somehow be altered; however, solar changes are untouchable by humans so far.

The connection between anthropogenic changes and climate disturbances is supported due to the small dimension of the system involved. One set depends on Sun-Moon-Earth interactions; the other is the atmosphere and the Earth's surface, strongly connected with human activities.

Let us examine climate disturbances happening in the Earth's poles; they are partially linked to a warmer troposphere created by overpopulated areas and the degradation of the environment occurring by the events former discussed.

The troposphere and the stratosphere are parts of the atmosphere; the troposphere is a semi-adiabatic layer into the system, trapping most of the green gases emissions coming from the Earth's surface.

The whole atmosphere is partially isolated from external space. Therefore, most of the events happening on the ground bounce back to the Earth's crust or are confined to the lower layers of the atmosphere.

Finally, it is necessary to analyze the evolution of solar variability interferences on the Earth's surface. The main forces among the three bodies (Sun, Moon, Earth) are mechanical or electromagnetic. Electromagnetic emissions from the Sun hit our planet's magnetic shield; Moon interacts mechanically on Earth. 
On the other hand, the Earth has a Magnetic protective field protecting the surface from dangerous solar wind emissions.

The seasons on Earth are determined by the planet's axis position concerning the earth's rotation around the star. Some of the particles from the Sun to the poles and the effect is the aurora borealis.

\section{WILDFIRES' HISTORY IN THE USA}

Table 1 shows the wildfires in the USA in the last twenty years; they happened most in the summer or fall with exceptions as in 2011.

From Table 1 is constructed two plots; one shows the enhancement of the acres burned last twenty years; the other is the variation in the number of fires in the same period, Figure 1 and Figure 2. Figure 1 shows the wildfires in the USA in the period 2000-2020, 2020 when people were most outdoors due to the pandemic and isolation; the number of wildfires grew more than in 2015, the second year with more wildfires.

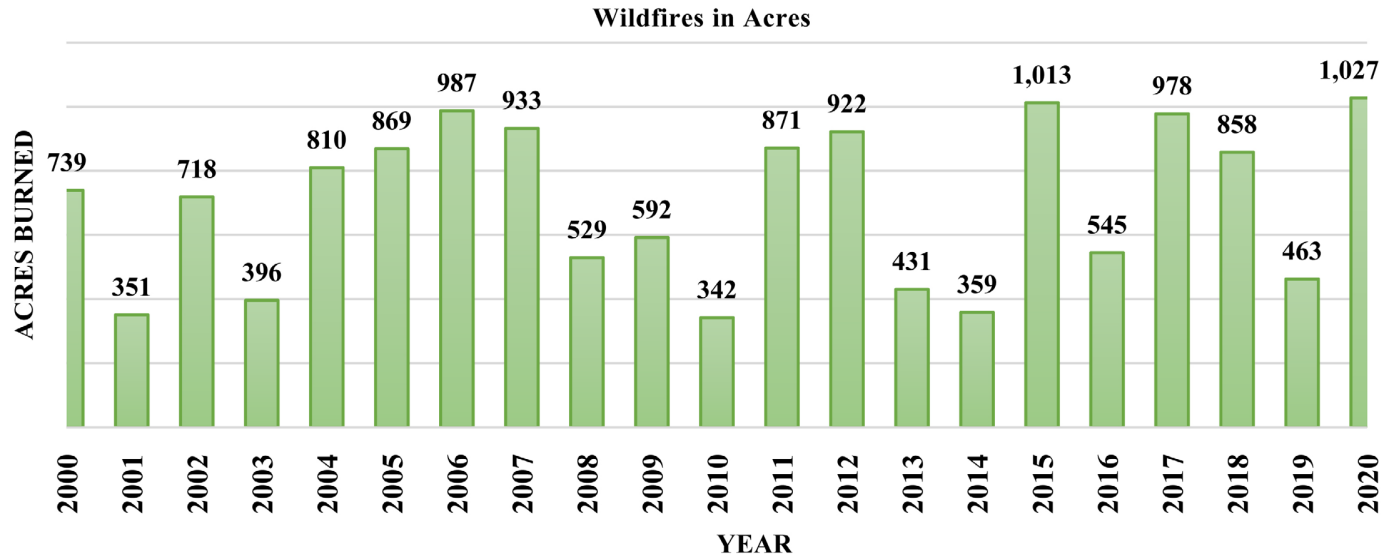

Figure 1. Wildfires acres for twenty years. The numbers are variable, but it suddenly increases again after a year or two with a small number of fires. For example, between 2004-2007 there was an enhancement year by year.

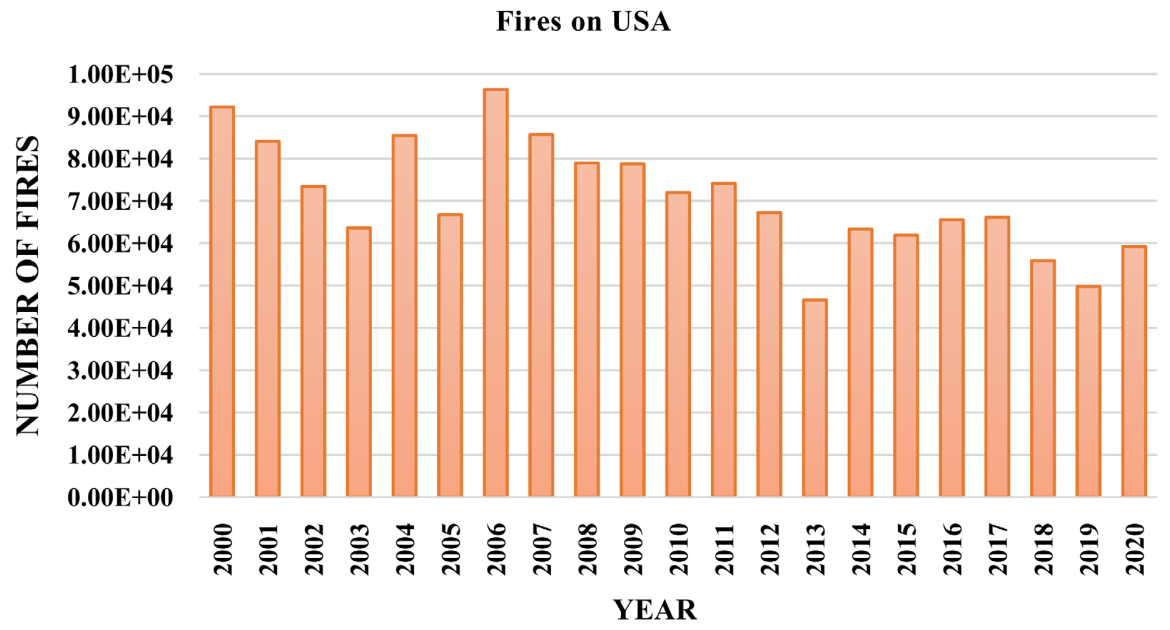

Figure 2. The number of fires in the USA decreased last few years; however, the area burned increased. It means people are hiking into more isolated places for camping, agriculture, and other human affairs. 
Table 1. Evolution of the wildfires last 20 years on the USA, 2000-2020. The second column is the number of acres burned, and the last is the number of fires. The National Center provided the information for Environmental Information (NCEI).

\begin{tabular}{|c|c|c|}
\hline \multicolumn{3}{|c|}{ Wildfires $2000-2020$ on the USA. } \\
\hline Year & Acres burned & Number of fires \\
\hline 2000 & $7,393,493$ & 92,250 \\
\hline 2001 & $3,509,911$ & 84,079 \\
\hline 2002 & $7,184,911$ & 73,457 \\
\hline 2003 & $3,960,842$ & 63,629 \\
\hline 2004 & $8,097,880$ & 85,461 \\
\hline 2005 & $8,689,389$ & 66,753 \\
\hline 2006 & $9,873,745$ & 96,385 \\
\hline 2007 & $9,328,045$ & 85,705 \\
\hline 2008 & $5,292,468$ & 78,979 \\
\hline 2009 & $5,921,786$ & 78,792 \\
\hline 2010 & $3,422,724$ & 71,971 \\
\hline 2011 & $8,711,367$ & 74,126 \\
\hline 2012 & $9,221,639$ & 67,266 \\
\hline 2013 & $4,307,176$ & 46,615 \\
\hline 2014 & $3,587,561$ & 63,345 \\
\hline 2015 & $10,125,149$ & 61,922 \\
\hline 2016 & $5,446,520$ & 65,575 \\
\hline 2017 & $9,781,062$ & 66,131 \\
\hline 2018 & $8,582,609$ & 55,911 \\
\hline 2019 & $4,630,007$ & 49,786 \\
\hline 2020 & $10,274,679$ & 59,258 \\
\hline
\end{tabular}

Data: National Center for Environmental Information. Information (NCEI).

Comparing Figure 1 and Figure 2, the conclusion is that last year (2020), humans searched for wilderness the previous year, where they would be isolated from the pandemic. Observing the area burned is larger than the number of fires.

We noticed the area burned was much higher than the fires themselves. Observe the plot 2020 when the pandemic was stronger; However, the number of fires was smaller, the area became more significant, meaning that people invaded the wilderness to keep isolated from each other.

A few hundred years ago, most forest fires happened by natural causes like lightning, volcanic eruptions, or earthquakes in specific geographic areas. 
Fires of natural origin are often quickly channeled since they usually have only one outbreak. Nowadays, most fires happen during the Summer or Fall, eventually, late Spring; therefore, it is possible to affirm that wildfires enhance during seasons. Nevertheless, $85 \%$ of wildfires originated from anthropogenic actions. Human-caused fires result from campfires left unattended, debris burning, equipment used and malfunctions, negligently discarded cigarettes, fireworks, and acts of arson [9-12].

The worse results have been in 2015 and 2020 when the fires reached more than 10,000 acres, with the interesting fact that in 2020 the number of fires was higher, but the area damage was less significant. Most wildfires are anthropogenic causes since natural causes such as lightning in some locations do not exist. Since 2000, three years had the highest number of ignited fires in the USA, in 2006 with 96,385 fires, followed by 2000 with 92,250 and 2007 with 85,705. [10, 11] Although in 2015 the number of fires was not high compared to other years, the area burned was the second extreme in the period analyzed. Taking 2000 and 2006 the number of fires was high, burning less significant areas, meaning the fires damaged reduced areas as Figure 2 and Figure 3 shows.

The consequences after fires are deforestation and consequent drought even though the start of agriculture in the locations. There is also a surge of micro weather modification in the area affected by the fires, the creation of mono agricultures, or other human proposals in the place burned [12-16].

Figure 3 shows the enhancement and evolution of wildfire in the conterminous USA, since early 1990 thoroughly 2020. The consequences have been the devastation of areas with old trees and the changing landscape. The importance of wildfires and the correlation with human activity is essential to climate change and the ecosystem.

Wildfires enhance in a region with population growth. Humans deforest areas are starting monocultures as soy, corn, beans, the wildlife decreases. There are indications that those fires connected with the surge of agricultural and cattle are associated with floods.

It is also connected with the lower layers of the atmosphere suffering unexpected evaporation after the extensive burning on the location. The climate consequences indicate that the changes and perturbations on the ground last for long.

Human growth in a location implies the spending of more fuel, a rise in agriculture, and cattle. The gases emissions as $\mathrm{CO}_{2}$ and methane will enhance as well. It is established that wildfires relate to those emissions, depending on anthropogenic factors.

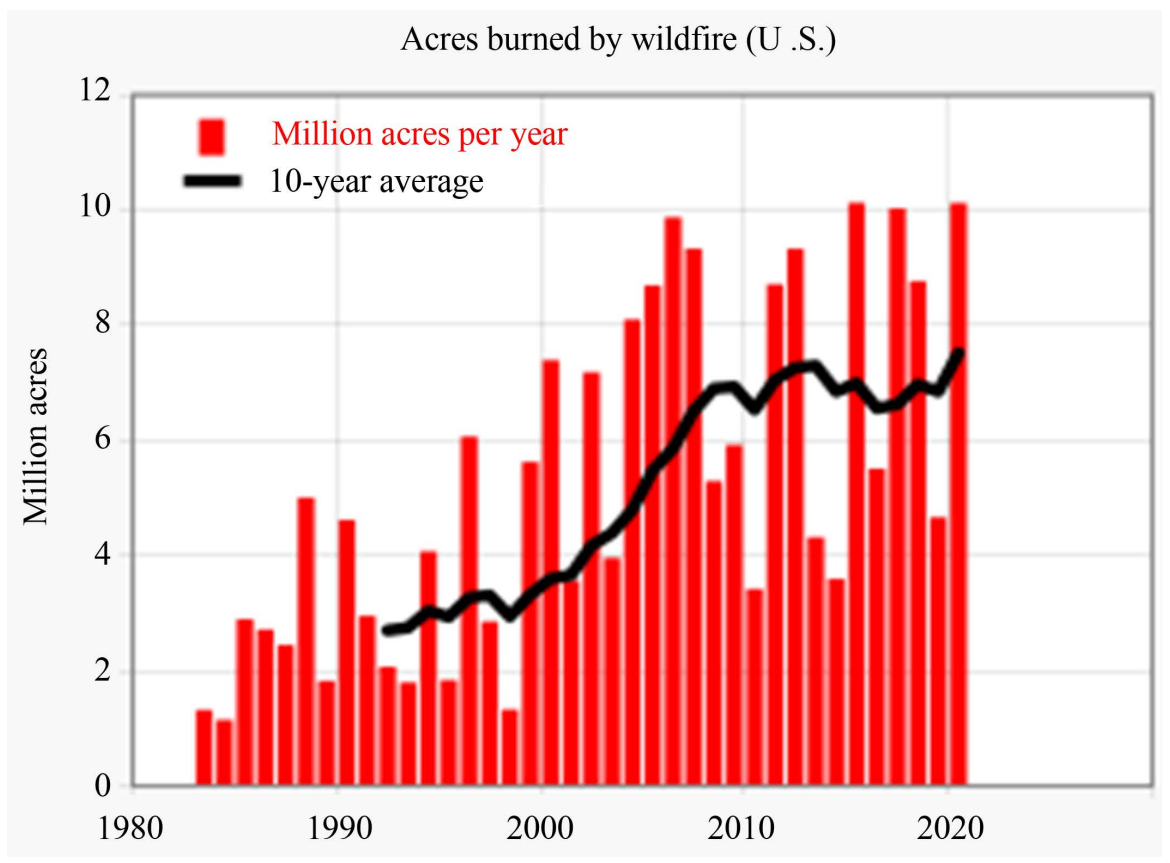

Figure 3. Increasing of acres burned by wildfire in the USA [5]. 


\section{DROUGHTS CONNECTIONS WITH THE WILDFIRES}

Droughts and fires connections are complex. Some problems are timing, frequency of droughts events, and diverge in the impacts on fuel flammability and fire behavior. For example, rapid drying of abundant fuel in forests, understories, and grasslands would feed larger fires after a wet spring. Somehow, the prolonged droughts limit fire incidents as the availability of fuels (grasses) are reduced due to lack of precipitation. The impact of droughts on humans is the water supply for drinking, agriculture, and health. Wildfire potential can be minimized in forests in the West and the South by thinning trees, prescribed burning, and letting fires that do not affect people's burn. Wildfire, a critical ecosystem process, is a global phenomenon divided into natural (lightning, or volcanoes, earthquakes) and human-caused ignition sources [16].

As fuels for wildfire, grasses, and trees, drought conditions can dry out and become more flammable. Drought may also increase the probability of ignition and the rate at which fire spreads. Hot temperatures link another factor intensifying the droughts. If combined with meager precipitation and snowpack, extreme heat decreases streamflow, dry soils, and significant-scale tree deaths. Such conditions increase the potential for severe wildfires that spread rapidly, burn with more severity, and are costly to suppress.

Droughts have other consequences for the wildfire's potential, reducing the amount of vegetation to burn decreases in the affected area.

Those are the existing procedures to reduce damaging wildfires and maintain ecosystem health. However, it is still a challenge to fire suppression efforts and budgets. In addition, projected warmer temperatures and an increase in the frequency of drought in several locations require an update in historical approaches to fire management.

\section{FLOODS LINKED TO WILDFIRES}

The next step in this paper is to search for a connection's wildfires and floods. It is hard to describe since the floods are most consequential from the heavy rains what are dependably also from atmospheric conditions. Wildfires change the landscape and ground conditions, leading to an increased risk of flooding during heavy rains once the burned ground cannot absorb the falling rain, producing surplus conditions like a parking lot. A consequence of this condition is converting a modest rainstorm over a burned zone in a flash flooding stream area.

Flooding is more extensive after subsequent wildfires since the ground is suffering the devastation in the affected area by burning. A place without vegetation quickly overflows with the same amount of rain. These floodwaters transport surface debris as downed trees, boulders, and gravel, this hazardous event becoming frequent along the US coastline. The rate of increase is accelerated at most locations along the East and the Gulf Coasts. The East Coast suffered more frequent coastal flooding and experienced significant increases in flood days. Boston, Massachusetts, for example, has exceeded the flood threshold most often, since 2011, an average of 13 days per year=, followed by Bar Harbor, Maine, and Sandy Hook, New Jersey. It is possible to show that from the 1950s, the increase of floods in those locations is now at least five times more common [14].

Though, flooding has increased less in places where the relative sea level has not risen as rapidly as elsewhere in the USA (for example, Hawaii and the West Coast).

\section{SUN CLIMATE CHANGES}

The energy from the Sun reaching the magnetosphere is named "total solar irradiance" (TSI). TSI varies slightly every day; in addition to the short-term fluctuations, there is an 11-year solar cycle related to sunspots. The change in solar energy is most remarkable at ultraviolet (short) wavelengths (Figure 4).

This short wavelength radiation modifies the ozone concentration at an atmospheric level above typical weather. Theoretically, these perturbations alter the clouds' cover and temperatures around the globe.

The 11-year solar radiation cycle appears to be correlated with alterations in cloud patterns. The solar 

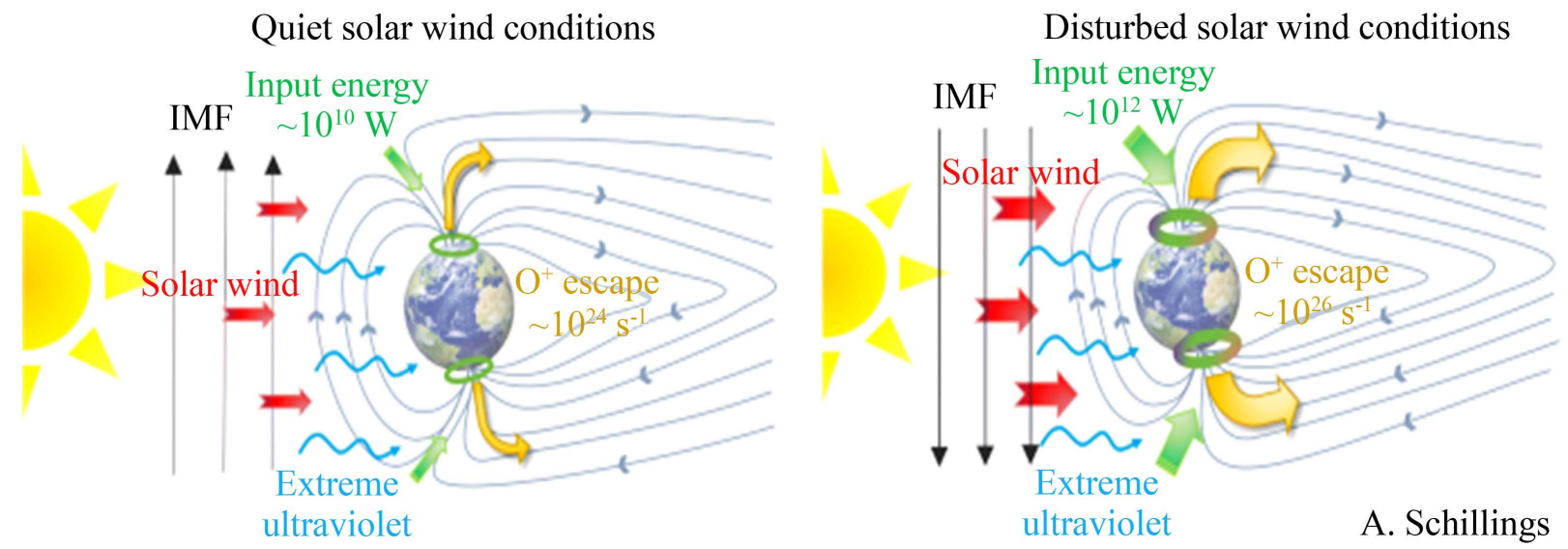

Figure 4. Conditions of solar wind in relation to the earth (18).

energy absorbed by the Earth changes with the processes decreasing or increasing periodically but is small and weaker than the anthropogenic disturbances in some Earth's surface areas. Most solar energy that hits the magnetosphere cannot penetrate the shield created by the earth's magnetosphere. However, some particles are trapped in the higher levels of the atmosphere, for example, into the plasmasphere. As a result, the ionized elements cannot reach the Earth's surface. The perturbation observed from the ground made anthropogenically reaching only the troposphere, the stratosphere [17].

The dimensions in the set Sun-Earth show that solar energy affects Earth's system. An example is the Seasons depending on the angle and rotation of the Earth around the Sun. Northern Hemisphere, covering $40 \%$ landmass and $60 \%$ water. The Southern Hemisphere has $20 \%$ landmass and covers up $80 \%$ water. Land warm faster than the Oceans, so the Northern Hemisphere is heating twice more quickly than Southern. Then, factors such as the anthropogenic density distribution and comparative landmass temperatures affect more disturbances in the Northern Hemisphere temperatures during the last sixty years.

The number of sunspots varies within an 11-year cycle to process a 10 - 12 years period. The effects of increasing sunspots are electromagnetic; it means a higher number of auroras on the poles, geomagnetic storms, which depending on the intensity, can disrupt power lines [1,2].

The British astronomer Maunder discovered that the unusually wintry weather that hit Europe between 1645-1715 was because the number of sunspots from cycle to cycle was behind the deadly cold spell during the period, named Maunder Minimum after him. Although scientists argue that the number of sunspots during the solar minimum has decreased in each cycle, they predicted another Maunder Minimum approaching fast. However, others claim that the following processes be more potent than the previous ones. First, the solar cycle 24 showed to be smoother than the formers; therefore, theories considering the subsequent cycles would be more substantial have already failed. Solar activity rising beginning at last century through the 1950s matched with the enhancement in global temperatures; the link did not hold up from the 1970s to the present. Therefore, our study shows other factors during these last few decades, including greenhouse gases in the atmosphere that dominated the higher temperatures scenario.

\section{EARTH'S ATMOSPHERE CONNECTIONS WITH THE GROUND}

The earth's surface intricately connects with the troposphere, the lowest layer of the atmosphere. The troposphere ( 0 - 10 Miles) is the layer of the Earth's atmosphere where all human activity occurs.

The weather happens at this level. As a result, the warmer pollutants gases from the earth's surface are driven vertically, as shown in Figure 5.

The warm pollutant elements discharged from several sources are released to the troposphere. The pollutants are divided into gaseous air pollution and particulate contaminants. Gaseous air pollutants 


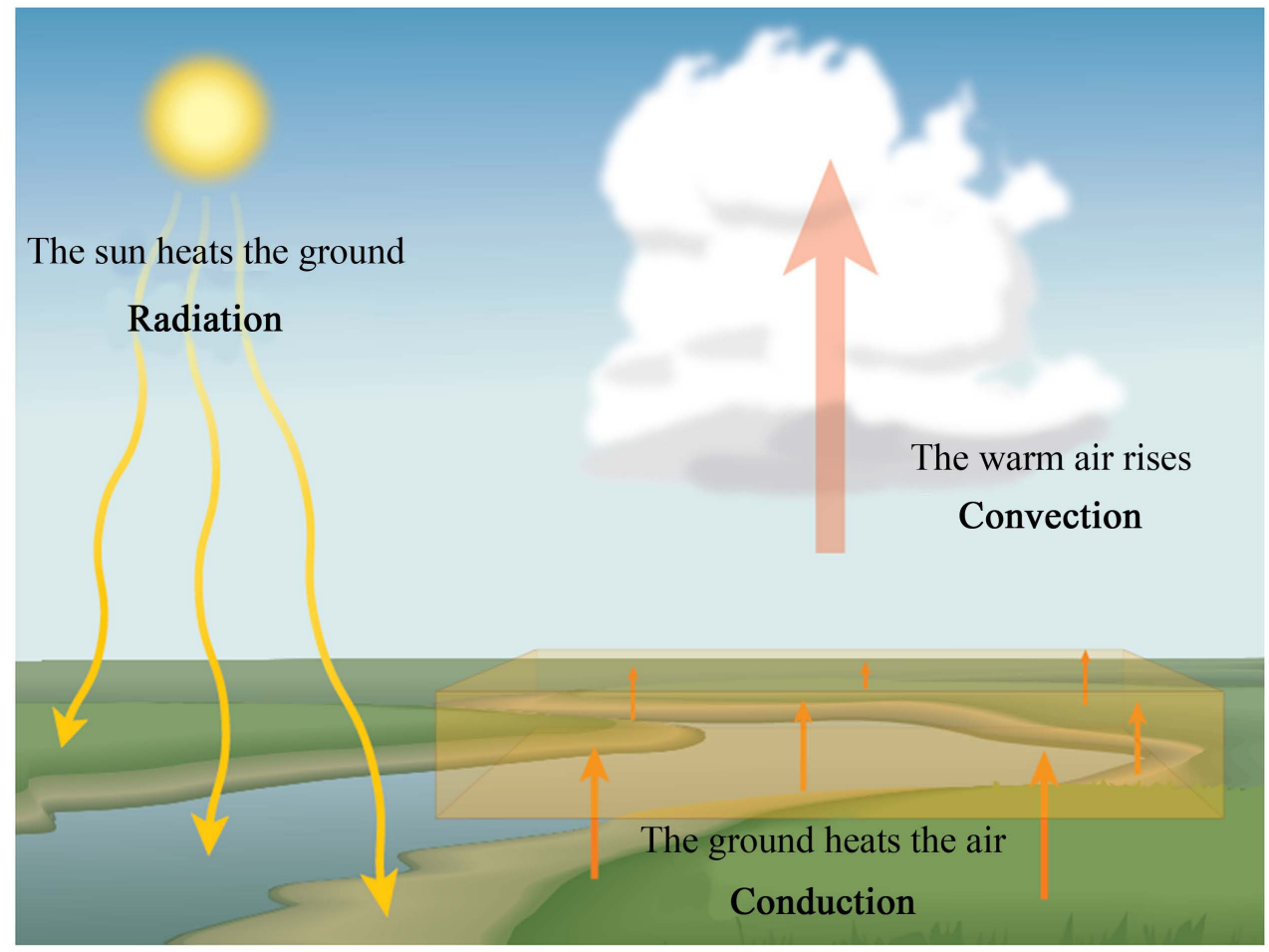

Figure 5. Shows how the sunlight hits the ground. Some of the energy is bounced back by evaporation orharmful gases emissions to the troposphere [18].

comprehend oxides of sulfur, nitrogen oxides, hydrocarbons, carbon dioxide oxides of carbon. Particulate pollutants happen in several diverse ways.

Smoke during combustion of the following elements,

1) Garbage burning of fossil fuels smoke from the burning of oil,

2) Dust sand, sawdust, fly ashes,

3) Mist from herbicides and insecticides,

4) Fumes condensation of vapors during distillation, boiling.

All those elements are vertically dragged to the troposphere. In addition, people also bury harmful materials on the ground for atmospheric pollution. An average American produces $2.0 \mathrm{~kg}$ of waste a day. Greenhouse gases discharges would decrease with prevention measures as fewer gas pollutant emissions.

Land pollution means that liquids and solid waste material are disposed of on the land surface or buried underground. Land pollution is produced by industrial activity, first connected with steel and coal, nowadays also linked to nuclear waste.

Batteries, electronics, cleaning material, heavy metals, or threatening pathogens are hazardous waste. As a result, a strict policy has been developed to deal with those materials.

Yet, cleaning the crust, including the oceans, would take ten to fifty years. The troposphere has a semi-adiabatic behavior acting as a blanket on the Earth's surface. Human emissions to the lower atmospheric layer become trapped, natural recycled by forest which now are devastated subject to bad management on the whole country.

The stratosphere is a region with intense interactions among radiative, dynamical, and chemical processes. The horizontal mixing of gaseous components proceeds rapidly compared with the vertical mixing. A bond between the stratosphere and troposphere is made by gravity waves generated in this region. Quasi-biennial oscillation $(\mathrm{QBO})$ in the tropical latitudes induces a secondary circulation important for the global stratospheric transport of traces such as ozone or water vapor. Figure 6 draws the lithosphere; the only part reached by humans is the crust of the earth's surface. 


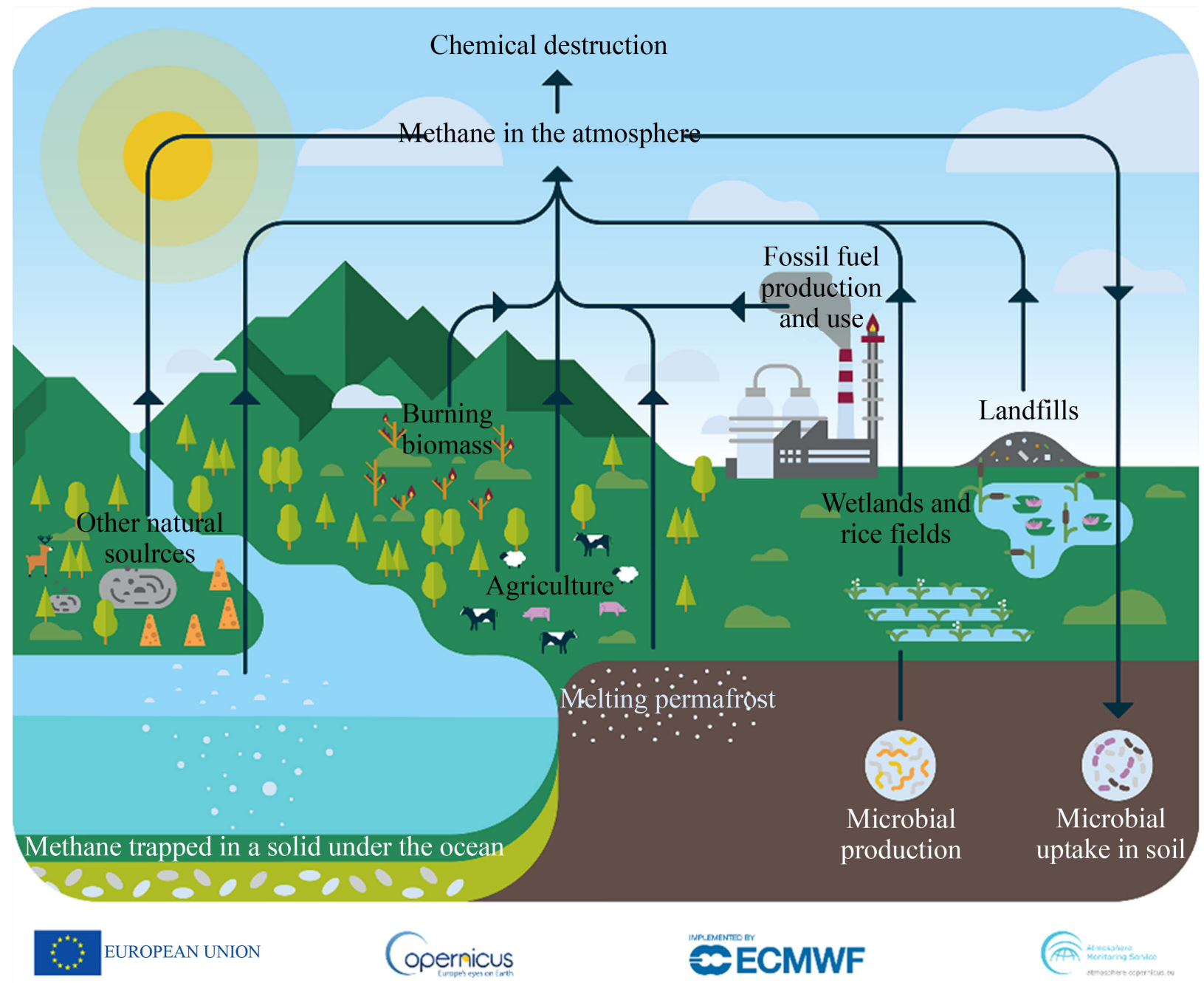

Figure 6. Shows methane enhancement in the atmosphere from the Earth's crust and several other sources [18].

This paper focuses on four levels of the atmosphere: thermosphere, mesosphere, stratosphere, and troposphere. Only the stratosphere and thermosphere are heavy perturbations by humans. From the Sun, the disturbance on the ground happens more at the poles occurring in the auroras.

Look at Figure 6; every winter takes place tropospheric vortex. Sudden Stratospheric Warming disrupts the stratospheric polar vortex that begins with large-scale atmospheric waves or Rossby waves being pushed higher into the troposphere. Strong wind waves weaken and reverse the polar vortex from westerly to easter. With the advances to cold air descending and warming rapidly, there is a sudden jump in temperature, leading to a displacement or splitting of the polar vortex. Instead of freezing air being locked above the polar region, it can push further south into mid-latitudes. As a result, the cold Arctic air is brought down into the mid-latitudes. Eurasia and North-America are affected by the Arctic warming two or three times faster than the rest of the planet.

\section{Atmospheric Contamination}

The main problem for the earth is that the harmful emissions cannot escape to higher atmospheric layers. Instead, the lower regions cover the Earth's surface like a blanket on the locations with more emissions $[18,19]$. 
The troposphere acts as an adiabatic system; gases inside become trapped, a small portion is organically recovered. Greenhouse gases naturally recycled are chemical reactions in physical exchanges between the atmosphere and the oceans.

Plants can remove carbon dioxide as they grow and store carbon, depending on the seasons. However, in the winter, the plants become unable to perform the entire process.

Forests and soils absorb more carbon than release it. Nevertheless, since 2000 forests have been devastated by anthropogenic needs. The ground is polluted by fertilizers and contaminated with other elements; hence it is impossible to absorb more carbon. As a result, the relationship between carbon dioxide and forest absorption is compromised. The consequence of gases entrapped into the atmosphere is the enhancement of the Earth's surface temperatures.

The methane cycle (one of the greenhouse gases) in the troposphere is shown in Figure 6.

The methane released to the atmosphere has several sources from the ground. Most of them are from human disposals as agriculture, rice fields in wetlands, landfills (breaking down organic material into methane), cattle, fossil fuel production (enhanced with fracking), burning biomass, and other natural sources.

Methane comes from a wide range of natural and anthropogenic sources. Wetlands produce the most significant methane emissions by the anaerobic decomposition of organic matter. Their methane production rate is strongly influenced by temperature, and its optimal range is between $37^{\circ} \mathrm{C}$ and $42^{\circ} \mathrm{C}$. In the oceans, methane production arises from methanogenic bacteria.

Anthropogenic factors such as containing fertilizers, effluents from waste treatment facilities provide nutrient-rich waters for methanogenic bacteria. It is supposed that human activities are responsible for $60 \%$ of methane emissions from extracting coal and leakage from processing natural gas being significant contributors. This gas escapes into the atmosphere unless it is mitigated using impermeable liners and capping layers. Burning biomass makes carbon dioxide, but methane and other organic compounds are produced if combustion is incomplete. The natural recycling of atmospheric methane into less harmful products occurs through chemical and biological processes. The nearest layer to the Earth's surface, the troposphere, reaches $13 \mathrm{~km}$ above sea level and contains over 75\% atmospheric gas. The colder air lies on the top of warmer air in this layer; the troposphere sees vertical mixing, oxidizing methane, removing 506 Mt per year. The stratosphere above the troposphere is cooler and less dense. Some methane enters the stratosphere from the layer below and is oxidized by chemical reactions amounting to $40 \mathrm{Mt}$ of methane removal per year. Lastly, soil bacteria can oxidize methane when the atmospheric gas encounters the ground.

The gases sent to the atmosphere are reprocessed in natural ways, as shown in Figure 4. Due to the increase of the human population, the emissions grew more than expected to physical recovery. The lower layers from the atmosphere receive dangerous emissions, heating too fast to be recycled. Human emissions rising last fifty years made it impossible for the hazardous pollutants to be reprocessed by organic means.

Fossil fuel use is the primary source of $\mathrm{CO}_{2}$, which can be emitted from direct human-induced impacts on forestry and other land use, such as deforestation, land clearing for agriculture, and degradation of soils (Figure 7).

This figure shows the increase of global population period 1900-2020 and global $\mathrm{CO}_{2}$ emissions. They grew together. The worldwide population now is above seven billion people, and $\mathrm{CO}_{2}$ is $\mathrm{MMTC}$ (milliontons of carbon). All countries with the most harmful emissions as China, the United States, European Union, India, and Russia located in the Northern Hemisphere with six and a half billion citizens.

Land can also remove $\mathrm{CO}_{2}$ from the atmosphere through reforestation, improvement of soils, among other activities. Methane $\left(\mathrm{CH}_{4}\right)$ is created by agricultural activities, waste management, energy use, and biomass burning. There is also Nitrous oxide $\left(\mathrm{N}_{2} \mathrm{O}\right)$ coming from farm activities, such as fertilizer use, primary sources of those emissions. Fossil fuel combustion also generates $\mathrm{N}_{2} \mathrm{O}$. Fluorinated gases (F-gases), industrial processes, refrigeration, and the use of a variety of consumer products contribute to emissions of F-gases, which include hydrofluorocarbons (HFCs), perfluorocarbons (PFCs), and sulfur hexafluoride $\left(\mathrm{SF}_{6}\right)$. This last one mentioned has an average lifetime in the atmosphere as few weeks to thousand years. Finally, black carbon is a solid particle or aerosol, not a gas, but it also contributes to warming the atmosphere (Figure 8). 


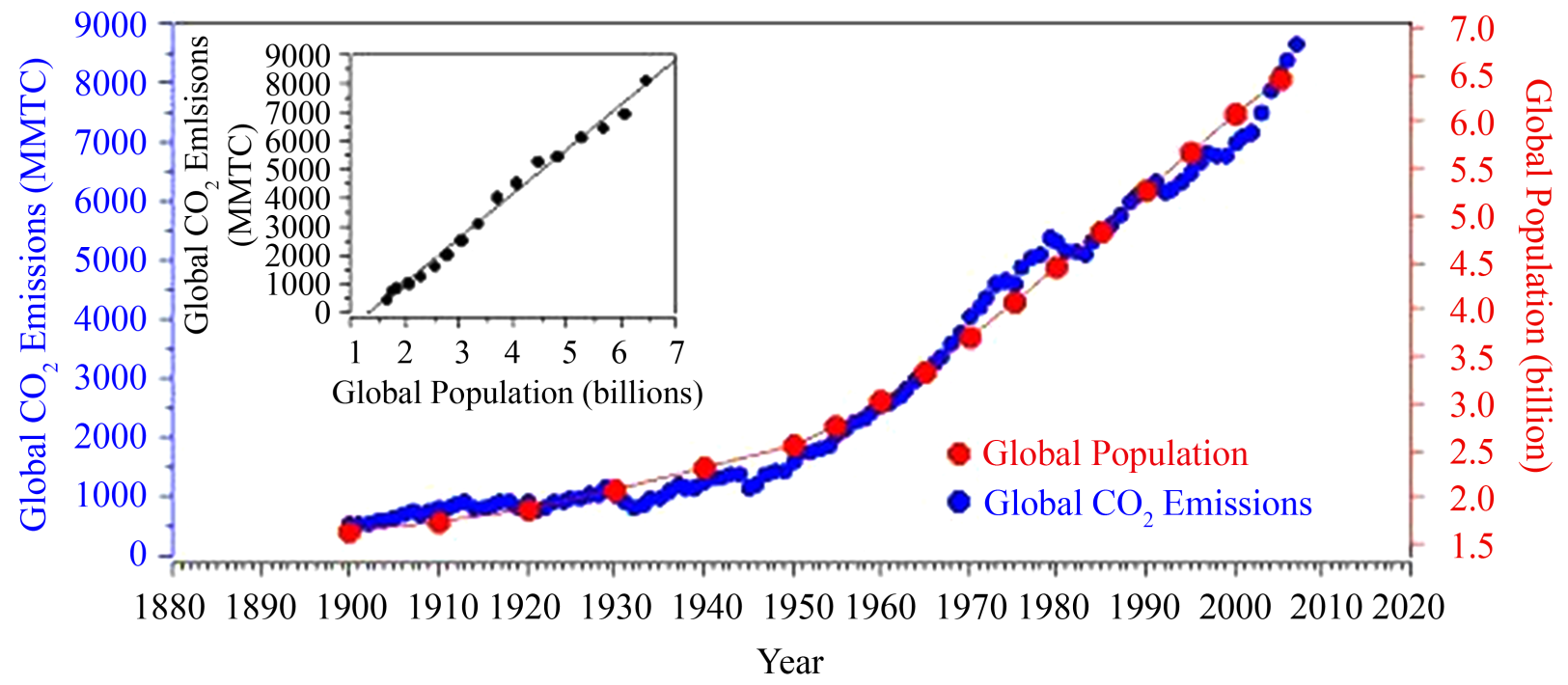

Figure 7. Average emission of $\mathrm{CO}_{2}$ at the atmosphere [19].

\section{COMBINED HEATING INFLUENCE}



Figure 8. This graph shows the heating imbalance caused by the significant human-produced greenhouse gases: carbon dioxide (gray), methane (dark purple), nitrous oxide (medium purple), chlorofluorocarbons (CFCs, lavender), hydrochlorofluorocarbons (HCFCs, blue), and hydrofluorocarbons (HFCs, light blue) [20].

Figure 8 points to the carbon dioxide as the gas that most increased. The F-gases had a minor enhancement in the period 1980-2020 show the HFCs did not exist until 1990. All the F-gases rose $47 \%$ since then. 
The results pointed out that gases expelled to the atmosphere after 1960 could not be recycled naturally since the atmosphere was half isolated from outer space. The system continuously keeps the Earth's crust's warmth following population enhancement and the growth of dangerous emissions $[15,16]$.

\section{IMPORTANCE OF POLAR CAPS IN THE GLOBAL WARMING}

There are two polarcaps on Earth; the one in the North Pole in the Arctic covered by sea ice reflects about $90 \%$. The solar energy reflected is named albedo (Figure 9).

The Arctic Ocean has lost about $40 \%$ of its ice in the past four decades. Less ice in the Arctic Ocean and black open water absorbs more solar energy and cause faster water warming. More ice is melted, which opens more water up [17]. It affects the global weather; as the sea ice disappears, currents and prevailing wind patterns are massively disrupted, causing more extreme weather and prolonged meteorological events such as droughts.

In the Arctic, the "old" ice is disappearing during summer. Young ice melts much faster in each ear. The Greenland ice sheet is crossing a tipping point. The global weather effect: when polar sea ice melts, the jet stream goes haywire. The extreme weather we are experiencing is partially attributable to Arctic Sea ice loss. The polar caps have three ice kinds that are rolling the global warming; one is the land ice when it melts, contributing to the total volume of water in the oceans. There are hundreds of feet of sea-level rise locked in the ice sheets of Greenland and Antarctica. In Antarctica, the continental landmass is twice the size of the United States. Although the interior glaciers are melting and the coastal ice shelves that hold them back are virtually collapsing, tons of reflective snow and ice is located on a vast landmass. Only about $30 \%$ of the solar energy is absorbed in the South Pole, which the remains are reflected into space. Therefore, the similarities in warming rates at the two opposite ends of the planet is, the Antarctic land ice melt is six times faster than the 1980's rate. East Antarctica is in the preliminary stages of collapse. Antarctica sea ice is at historic lows [21]. Melting glaciers in Greenland and the Antarctic drive freshwater, pouring it into the oceans and slowing down global currents. Differences in salinity between depth layers drive the global overturning wind.

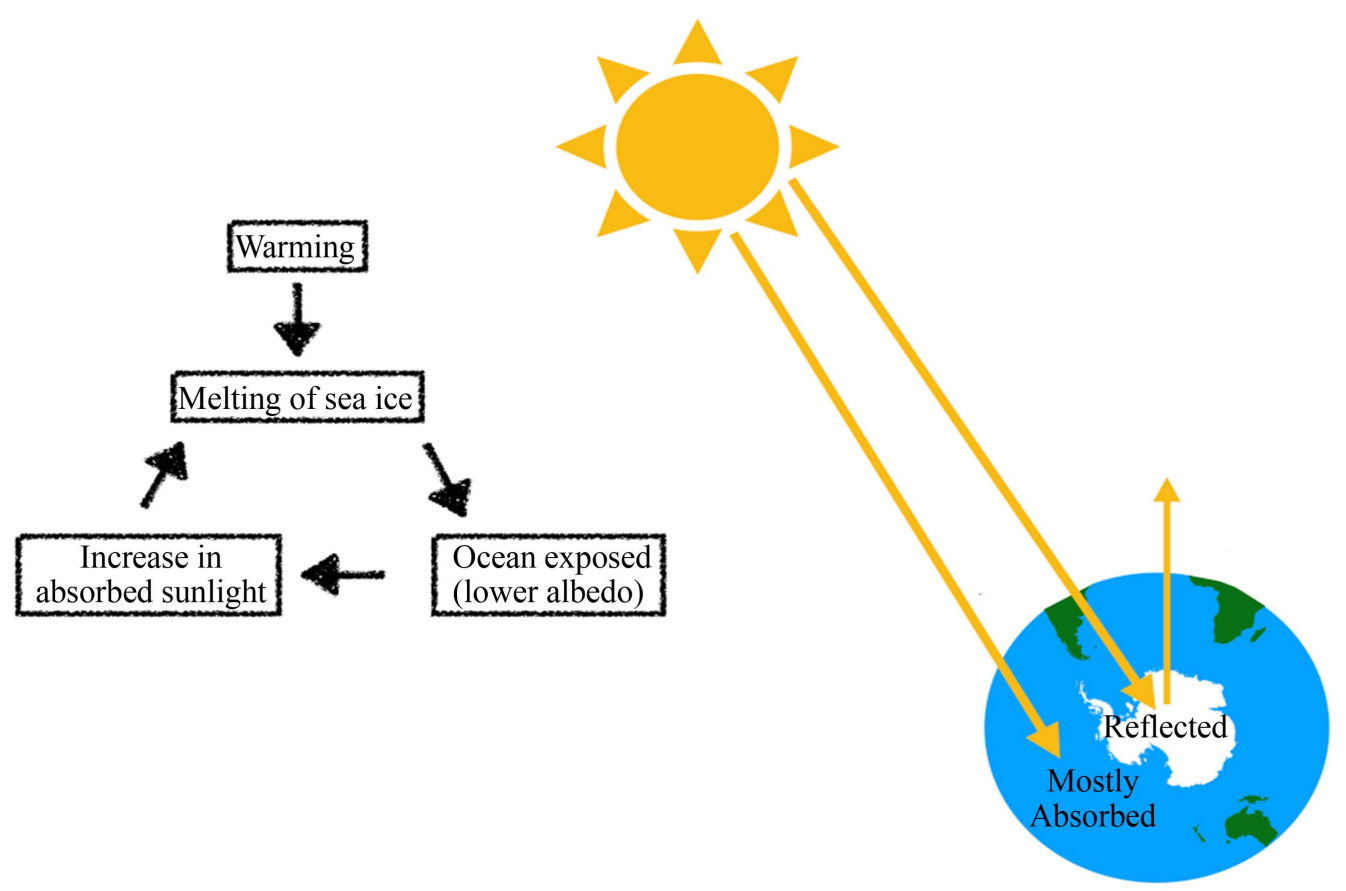

Figure 9. The figure explains why the Arctic is melting faster (By Tovarg, Own work, CC BY-SA 4.0, https://commons.wikimedia.org/w/index.php?curid=79657236). 
Shelf ice is a hybrid ice-class critical to melt rate for onshore ice sheets. To a large degree, ice shelves are holding back the flow of glaciers into the ocean, especially in Greenland and Antarctica. As the Antarctic ice shelves break up, the land ice behind them begins to flow faster. Finally, the sea ice that floats in the water and its effects on climate is tricky to measure, but general trends are clear. The extent of ice pack decline has been verifiable for decades, with the total area covered reduced by about $70 \%$ since 1978 . The fast melting of sea ice is one of two primary polar feedback loops accelerating global warming to no return.

The importance of ice melting in global warming affecting the environment is due to the declination of the albedo in the areas. The diminishing of Arctic albedo has made the summer Arctic Sea shrink in recent decades. Suppose more solar energy is absorbed by the ocean, air, and icy landmasses. In that case, it enhances the ongoing warming in the region, which is more pronounced than anywhere else on the planet. The solar radiation absorption in the Arctic happens most in July and August [21].

The absorption of solar radiation is about 10 Watts per square meter. Some locations as the Beaufort Sea experienced the most pronounced decreases in sea-ice coverage, a 50 Watts per square meter increase. The Arctic shows more dramatic signs of climate change than other parts of the whole planet. It warms the air temperatures at a rate two to three times greater than the rest of the Earth, which affects the air temperatures in the USA and Eurasia continents. This study concluded that in the Northern Hemisphere, the Arctic affects the temperatures in the continents surrounding the area. Such evidence was not found in the Antarctic; however, it makes similar catastrophes in the Southern Hemisphere. The third factor that enhances the Earth's surface temperatures is analyzed next paragraph.

\section{GROUND CONTAMINATION}

Land pollution can happen in any number of ways. Acid rain can contaminate the soil and tainted water absorbed by the Earth. Pollutants in the soil can contribute to air and water pollution; it is a full circle. Soil pollution differs from land pollution; the causes and effects are mostly the same. Land pollution affects everything that lives on Earth, plants, wildlife, humans, and soil. The human population continues growing as our activities. The solution is to learn how to lessen our harmful actions. Lower carbon footprint, watch our energy usage, recycle more items, using renewable resources for power. Humans most disturb the atmosphere, the lower layers. The ground or crust is barely touched; the deepest hole in the world had The Kola Superdeep Borehole was just 9 inches in diameter, but at 12,262 meters reigns as the deepest hole. Therefore, any human perturbation on the crust is not strong enough to make any difference at the Earth's surface.

The anthropogenic fact is that the population density is 6.5 times higher in the Northern Hemisphere; therefore, the ground emissions are six and half times more than in the Southern.

The leading causes for soil pollution are trash, chemicals, a contribution from other toxic waste types. Farmers use pesticides to protect their crops. Although at the same time, they may promote plant growth, they contain harmful chemicals absorbed into the soil. Pesticides and other chemicals increase the salinity of the ground, making it imperfect for crop bearing, affecting the microorganisms that help the soil and plants function. Two kinds of organic pollutants have a biological origin: acid rain resulting from air pollution. The inorganic contaminants are manufactured. They often come from industries and construction companies, detergents, cosmetics, chlorinated solvents, hydrocarbons, heavy metals from sulfur dioxide, chemical waste, silt from construction, and chemical fertilizers. They are introduced into the soil utilizing dumping, runoff, spills, or by direct means like nourishing crops. Toxic chemicals leak into the groundwater or runoff into nearby streams, lakes, or oceans.

It also contributes to air pollution by releasing harmful chemical compounds. The decomposition of organic materials into the ground releases sulfur dioxide and other sulfur compounds, causing acid rain. Some soil pollutants are carcinogenic to humans, likely to develop cancer. The contaminants that enter the soil can have long-lasting effects on the land: erosion. Erosion is when the topsoil is swept away by the actions of wind, water, ice, or gravity. Although some erosion is necessary, land pollution increased in these last years, which causes the land to lose its original soil structure and ability to support plant life. 
Another critical element of soil pollution is radioactive pollution, which is more contaminated in the Northern Hemisphere than in the Southern. Those are factors additional for human perturbations on the environment besides the Natural Hazard Events. It is strongly dependent on the Northern Hemisphere inhabitants; there are two reasons for them. The Northern population is six times higher than in the Southern, and the mass land is also more prominent in the Northern.

The reasoning behind this is simple, $90 \%$ of all nuclear weapons testing were done in the Northern, and some of the most notable atomic power-plant disasters occurred in the Northern. Nuclear weapons testing in the atmosphere accounted for considerable amounts of radioactive materials released directly into the environment. The environment includes the atmosphere and the oceans as well. The Fukushima nuclear disaster significantly contaminated the sea.

The occurrence of wildfires in a region enhances gases emissions, devastation in the areas affected by fires, floods, droughts leading to climate disturbances in the conterminous USA.

The Northern Hemisphere has more landmasses reaching temperatures two times faster than the Southern. Nevertheless, the mainland is cooling rapidly and has lower temperatures than oceans. Here we investigate most of the Earth's crust and the top of the ocean's water. A complete study would describe the current system for the seas, winds transportation between land and water, and varies from the lower latitudes near the equator to higher latitudes near the poles.

First, wildfires that lately relate to the human interferences in the Summer and Fall, in the conterminous USA, were examined. It is intense in the region due to the higher availability of data last decades.

Therefore, it is easier to develop any correlation among the three hazard events: wildfires, floods, droughts, from anthropogenic causes. For example, wildfires' natural causes are lightning, volcanoes, earthquakes; however, compared with the human performance, which is $85 \%$ of the incidences, it is small.

Wildfires happen most during Summer and fall due to increased human interactions with the area, like deforestation, pollutants discharges in the natural reserves as heavy metals into the oceans, lakes, rivers, soils, the rising of agriculture, fertilizers, and pesticides, improper growth disposal.

The three hazard natural events mentioned had a connection among them; most wildfires fed the low layers of the atmosphere with pollutants. Therefore, the ground contamination and the consequences of pollutants into the atmosphere by humans are more considerable than first considered. It happens by the wildfires, the discharge of contaminants and pollutants, and the gas emissions, as seen in Figure 7.

\section{EFFECTS FROM SOLAR EVENTS VERSUS ANTHROPOGENIC DISTURBANCES ON THE CONTERMINOUS USA}

The Earth is partially isolated from the Sun by the magnetosphere. It explains why the damaging radiation from the Sun cannot reach the crust. However, it also prevents Earth from setting free the excessive pollution or gases in outer space. As a result, it is producing a bubble of poisoning substances that jeopardizes the safety and health of humans.

All those elements are nurtured inside of an almost adiabatic system surrounding the Earth's surface, isolated by the lower atmosphere and endangering the ecosystem on the Earth's surface. The first part of the paper worked on three hazard events: wildfires, droughts, and floods, considering the last two as consequences from the first one.

The components to the system Earth/atmosphere are the troposphere, stratosphere (the lowest layers from the atmosphere), the ground or crust, the superior level of the lithosphere. In this set gases emissions are created from the world's surface and partially recycled in the troposphere, a small amount escaping to the stratosphere but most harmful emissions remaining into the troposphere. The solid pollutant material buried on the crust is superficial if we realize that the total depth of the crust is fifty kilometers.

The function of oceans should be considered; they are critical to climate change since they recycle lots of carbon dioxide. However, the ocean's approach is complex; there are several factors ocean currents, variability in temperature distribution by location and depth. Other issues as the discharge of pollutants, plastics, harmful hazards as nuclear waste, or disasters as Fukushima would be discussed. Nevertheless, it 
demands accuracy on the data we did not find.

The injection of a massive amount of waste indicates continental and oceans crust cannot recycle all polluting elements brought into the entire system.

Gases as methane and carbon dioxide disrupt the atmosphere, the discharge of heavy metal and other waste into the oceans or buried on the crust jeopardizes the entire environment. Adiabaticity or quasi adiabaticity explains the processes involving gases trapped in the troposphere. The harmful emissions are partially recycled naturally, becoming like a blanket on the Earth's surface.

The three-body system (Sun, Moon, Earth) has the mechanic interaction dependence of $F=1 / r^{2}$ where $\mathrm{r}$ is the distance between Sun-Earth, 150 million kilometers; therefore, mechanical perturbations are insignificant compared with the variability of the electromagnetic forces among these bodies.

The magnetic solar field magnitude is two times the magnetic Earth's field. The Sun's electromagnetic phenomena include coronal mass ejection (CME), flares, and sunspots which affect the particles that Sun ejects on the Earth's magnetosphere and cause sensations as auroral lights. Such events are not attached to changes in the Earth's surface temperature could influence other natural hazard events as earthquakes formerly discussed by the author [1-3].

It is necessary to discuss the interactions Sun-Earth as a system of two bodies; however, the Sun's dimension is 109 times larger than our planet, and the volume is 1.3 million times bigger compared with the world. Yet, the Earth's magnetic shield directly avoids the Sun's interaction on its surface.

Humans affect the atmosphere by discharging gases like methane, carbon dioxide, the continental crust, oceans, and continental lands, including pollution, heavy metals, and other contaminants. For two or three centuries, heavy metals, plastics, and nuclear waste have polluted the earth's surface. However, the lifetime average is four billion years.

In addition, there is a contamination of freshwater, fertilizers, the devastation of the primary forests, increasing cattle contamination, and pollution.

Old ecosystems are being destroyed; resources are exhausted, the landscape is being modified, overall, the natural systems have been strongly violated. The Earth's surface is trapped in an adiabatic system; elements coming from the Earth's surface are sucked into the atmosphere, all set in an isolated box.

Overall, the disruptions made by humans are faster, more effective from the ground than the ones coming from the Sun. Figure 10 the two superior layers, mesosphere, and thermosphere are barely

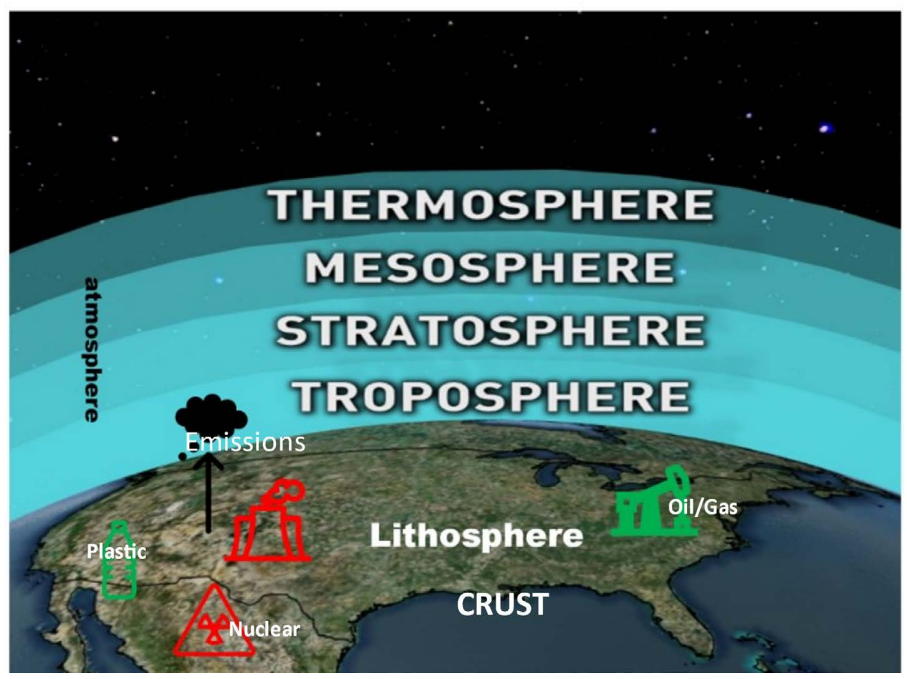

Figure 10. Disposition of Earth vs. atmosphere and its layers above the ground. The surface of the lithosphere (crust) receives human pollution, greenhouse gases, plastic, nuclear waste. The gases are released and trapped in the troposphere. Therefore, we show only layers of the atmosphere that fit our proposals. 
touched from the earth's soil. There are no perceived changes in those levels; the perturbations from humans only happen near the Earth's surface. There are some indications that anthropogenic processes become irreversible if people do not slow down the disruptions in the environment.

Therefore, it is paramount to work scientifically with the problem pointed out in this report. Our planet is protected from the harm radioactive from the Sun by our electromagnetic field; however, it is unprotected from the damage processed on the Earth's surface by several unnatural mechanisms described here.

The USA has had the most climate catastrophes observed in recent years, forest fires, droughts, and floods, partially caused by humankind. In addition, polluting gas emissions into the atmosphere have increased over the last twenty years because of population growth. As a result, seasonal temperatures have experienced unprecedented extremes between cold and warm.

The Earth's surface's anthropogenic disturbances affect the system in locations with the highest population growth. The instabilities created are not for the unusual temperatures observed during the seasons; also, it creases other parameters as floods and droughts. This research separated several issues discussed: anthropogenic wildfires and their correlation with droughts and floods, other issues with harmful emissions, and waste from humans. The main forces are acting on the three-body system. Those issues are compared, and the importance of human actions on the environment is highlighted.

\section{CONCLUSIONS}

This paper discussed the possible mechanisms of climate-change on our planet. There are two kinds of them, Sun-Earth, and the anthropogenic disturbances on the earth's surface. From the Sun, the most important is the electromagnetic emissions and seasonal variations on Earth; the mechanic connection is weaker among the two bodies since the distance is vast.

The other factor is the earth's surface emissions. In the last two centuries, the source of harmful waste to the troposphere enhanced. As a result, the entire environment is surrounded by pollutants and gases released directly to the troposphere.

The overpopulation concentrated in some regions creates harmful emissions released to the troposphere, some of which are agricultural activities, waste management, energy use, biomass burning, some radioactive materials buried in chosen areas around the country.

Earth ground emissions due to anthropogenic matters increased the wildfires, which are linked to floods, droughts, heavy showers, tornados out of the season, rise and drop in the average weather temperatures.

The atmosphere is exhausted trying to recycle greenhouse gases occurring weather disturbances. There are some indications that oceans play an essential role in the system. However, it was impossible to manage the data centers in this first attempt. The magnetosphere protects the earth from charged particles coming in the solar wind; they are trapped in various system layers such as the thermosphere or plasmasphere. An analogous situation happens from the earth's surface to the atmosphere, where greenhouse gases and other emissions are kept between the troposphere and the stratosphere.

The emissions have grown so much that natural means of recycling are no longer enough to defend the ground from catastrophic events. Partially the harmful emissions are recycled by oceans, vegetation on the earth, and some are released to the stratosphere. However, the recycling time is becoming slow to manage all the pollutants from the ground now. Those emissions and pollutants provoke the unusual effects observed on the ground with human growth. Our conclusions pointed out that humans became responsible for the heavy damage on the ground, disturbing the troposphere, realizing greenhouse gases, jeopardizing the ecosystems.

The solar connections and effects are strong; however, cannot make such changes observed nowadays which credit must be to human ways.

Our conclusion strongly supports that humans are responsible for the full set, atmosphere pollution, Earth's crust damages as desertification, and pollutant material accumulation on the ground. It also jeo- 
pardizes the ecosystems faster than the Sun.

\section{ACKNOWLEDGEMENTS}

Thank you very much for the anonymous reviewers. We are grateful for the suggestions and insights sent to us

\section{CONFLICTS OF INTEREST}

The authors declare no conflicts of interest regarding the publication of this paper.

\section{REFERENCES}

1. Azevedo, A. (2011) Influences of Solar Cycles on Earthquakes-Marilia Tavares. Natural Science, 3, 436-443.

2. Hagen, M. and Azevedo, A. (2017) Sun-Moon-Earth Interactions, External Factors for Earthquakes. Natural Science, 9, 162-180. https://doi.org/10.4236/ns.2017.96018

3. Hagen, M. and Azevedo, A. (2019) Sun-Moon-Earth Interactions with Larger Earthquakes Worldwide Connections. Open Journal of Earthquake Research, 8, 267-298. https://doi.org/10.4236/ojer.2019.84016

4. Balcha, J.K., Bradley, B.A., Abatzogloue, J.T., Chelsea Nagya, R., Fuscod, E.J. and Mahood, A.L. (2017) Human-Started Wildfires Expand the Fire Niche across the United States. Proceedings of the National Academy of Sciences of the United States of America, 114, 2946-2951. https://doi.org/10.1073/pnas.1617394114

5. National Interagency Coordination Center, National Interagency Fire Center (2021) Wildfire acres Burned in the United States. OurWorldInData.

6. Hawbaker, T.J., Radeloff, V.C., Stewart, S.I., Hammer, R.B., Keuler, N.S. and Clayton, M.K. (2013) Human and Biophysical Influences on Fire Occurrence in the United States. Ecological Applications, 23, 565-582. https://doi.org/10.1890/12-1816.1

7. Bistinas, I., Oom, D., Sá, A.C.L., Harrison, S.P., Prentice, I.C. and Pereira, J.M.C. (2013) Relationships between Human Population Density and Burned Area at Continental and Global Scales. PLoS ONE, 8, Article ID: e81188. https://doi.org/10.1371/journal.pone.0081188

8. Parisien, M.-A., Miller, C., Parks, S.A., DeLancey, E.R., Robinne, F.-N. and Flannigan, M.D. (2016) The Spatially Varying Influence of Humans on Fire Probability in North America. Environmental Research Letters, 11, Article ID: 075005. https://doi.org/10.1088/1748-9326/11/7/075005

9. Syphard, A.D., Radeloff, V.C., Keeley, J.E., Hawbaker, T.J., Clayton, M.K., Stewart, S.I., et al. (2007) Human Influence on California Fire Regimes. Ecological Applications, 17, 1388-1402. https://doi.org/10.1890/06-1128.1

10. Fusco, E.J., Abatzoglou, J.T., Balch, J.K., Finn, J.T. and Bradley, B.A. (2016) Quantifying the Human Influence on Fire Ignition across the Western USA. Ecological Applications, 26, 2390-2401.

https://doi.org/10.1002/eap.1395

11. Calef, M.P., McGuire, A.D. and Chapin, F.S. (2008) Human Influences on a Wildfire in Alaska from 1988 through 2005: An Analysis of the Spatial Patterns of Human impacts. Earth Interactions, 12, 1-17. https://doi.org/10.1175/2007EI220.1

12. Morton, D.C., Collatz, G.J., Wang, D., Randerson, J.T., Giglio, L. and Chen, Y. (2013) Satellite-Based Assessment of Climate Controls on US Burned Area. Biogeosciences, 10, 247-260.

https://doi.org/10.5194/bg-10-247-2013

13. Malamud, B.D., Millington, J.D.A. and Perry, G.L.W. (2005) Characterizing Wildfire Regimes in the United States. Proceedings of the National Academy of Sciences of the United States of America, 102, 4694-4699. https://doi.org/10.1073/pnas.0500880102 
14. Stephens, S.L. (2005) Forest Fire Causes and Extent on United States Forest Service lands. International Journal of Wildland Fire, 14, 213-222. https://doi.org/10.1071/WF04006

15. United States Environmental Protection Agency (2021, April) Climate Change Indicators: Coastal Flooding. https://www.epa.gov/climate-indicators/climate-change-indicators-coastal-flooding

16. Folger, P. (2017) Drought in the United States: Causes and Current Understanding. Congressional Research Service, Washington DC.

17. Herring, D. (2020) Are Humans Causing or Contributing to Global Warming? https://www.climate.gov/news-features/climate-qa/are-humans-causing-or-contributing-global-warming/

18. Schillings, A., Slapak, R., Nilsson, H., Yamauchi, M., Dandouras, I. and Westerberg, L.-G. (2019) Earth Atmospheric Loss through the Plasma Mantle and Its Dependence on Solar Wind Parameters. Earth, Planets and Space, 71, Article No. 70. https://doi.org/10.1186/s40623-019-1048-0 https://earth-planets-space.springeropen.com/articles/10.1186/s40623-019-1048-0/

19. https://atmosphere.copernicus.eu/index.php/ghg-services/methane-budget/

20. Easterbrook (2009) Population Growth vs. Emissions Growth. https://www.easterbrook.ca/steve/2009/06/population-growth-vs-emissions-growth/

21. Vihma, T. (2014) Effects of Arctic Sea Ice Decline on Weather and Climate: A Review. Surveys in Geophysics, 35, 1175-1214. https://doi.org/10.1007/s10712-014-9284-0 